University of Nebraska - Lincoln

DigitalCommons@University of Nebraska - Lincoln

Agronomy \& Horticulture - Faculty Publications

Agronomy and Horticulture Department

$7-2006$

\title{
Effect of cultivation and within-field differences in soil conditions on feral Helianthus annuus growth in ridge-tillage maize
}

\author{
Michael G. Burton \\ North Carolina State University \\ David A. Mortensen \\ Pennsylvania State University \\ John L. Lindquist \\ University of Nebraska-Lincoln, jlindquist1@unl.edu
}

Follow this and additional works at: https://digitalcommons.unl.edu/agronomyfacpub

Part of the Plant Sciences Commons

Burton, Michael G.; Mortensen, David A.; and Lindquist, John L., "Effect of cultivation and within-field differences in soil conditions on feral Helianthus annuus growth in ridge-tillage maize" (2006). Agronomy \& Horticulture -- Faculty Publications. 421.

https://digitalcommons.unl.edu/agronomyfacpub/421

This Article is brought to you for free and open access by the Agronomy and Horticulture Department at DigitalCommons@University of Nebraska - Lincoln. It has been accepted for inclusion in Agronomy \& Horticulture -Faculty Publications by an authorized administrator of DigitalCommons@University of Nebraska - Lincoln. 


\title{
Effect of cultivation and within-field differences in soil conditions on feral Helianthus annuus growth in ridge-tillage maize
}

\author{
Michael G. Burton, ${ }^{1}$ David A. Mortensen, ${ }^{2}$ and John L. Lindquist ${ }^{3}$ \\ ${ }^{1}$ Department of Crop Science, North Carolina State University, Campus Box 7620, Raleigh, NC 27695, USA \\ ${ }^{2}$ Department of Crop and Soil Sciences, Pennsylvania State University, 116 ASI Building, University Park, \\ PA 16802-3504, USA \\ ${ }^{3}$ Department of Agronomy and Horticulture, University of Nebraska-Lincoln, Lincoln, NE 68583-0915, USA \\ Corresponding author - M. G. Burton, tel 919 513-2860, fax 919 515-5315
}

\begin{abstract}
Differences in weed population dynamics with respect to within-field heterogeneity are not well documented despite increasing interest in site-specific management of agro-ecosystems. The focus of this study was to determine if mechanical weed management (cultivation) and/or soil factors help to explain observed within-field distributions of feral common sunflower (Helianthus annuus L.). The ridges and furrows created by the ridge-tillage system adds additional microsites to existing spatial heterogeneity for soil characteristics such as soil organic carbon (SOC) concentration. Experimental areas were selected on the basis of naturally high or low SOC concentration. Cultivation resulted in $100 \%$ mortality of $H$. annuus seedlings growing in the middle of furrows. Cultivation of pre-emergence herbicide treated and no-herbicide ridges resulted in small but statistically significant $(a=0.05)$ reductions in seedling survival. No differences were detected in $H$. annuus canopy height, stem diameter, stem length, or vegetative biomass between high and low SOC environments. Neither total reproductive biomass $(P=0.49)$ nor the biomass of flowers near physiological maturity (an estimate of fecundity; $P=0.59$ ) were affected by SOC environment. Late season $H$. annuus lodging was observed to reduce reproductive biomass. Juvenile plants that survived mechanical weed control efforts grew and produced reproductive biomass similarly across SOC environments. The lack of difference in vegetative and reproductive characteristics between high and low SOC environments suggests that SOC (or the edaphic conditions associated with greater or lesser SOC level) was not critical in contributing to the observed distribution of $H$. annuus from juvenile to flowering stages of growth within well-fertilized, irrigated agricultural habitats.
\end{abstract}

Keywords: soil organic carbon, soil organic matter, ridge-tillage, population dynamics, fecundity

\section{Introduction}

Site-specific application of weed management tactics may enhance our ability to manage economic inputs as well as natural resources. Lindquist et al. (1998) and Johnson et al. (1995) demonstrated potential economic benefits from managing spatially stable weed populations with site-specific herbicide application. Similarly, applying chemical weed 
management tactics according to soil characteristics (e.g., sorptive capacity, depth to groundwater, etc.), as opposed to applying a uniform herbicide rate across the field, may reduce the potential for ground or surface water contamination (Mitchell et al., 1996; Prather and Callihan, 1993; Wilson et al., 1993). An intensive soil sampling effort in Iowa demonstrated atrazine [6-chloro- $N$-ethyl- $N$ '(1-methylethyl)-1,3,5-triazine-2,4-diamine] sorption $\left(K_{\mathrm{d}}\right)$ ranging from 1.9 to 12.5 within a single 6.25 ha field (Novak et al., 1997). Areas with higher $K_{d}$ values would have reduced atrazine bioavailability under uniform application rates. Such differences in soil characteristics may influence seedling survival and, therefore, weed population dynamics (Burton et al., 2004).

If well-managed and coupled with an understanding of the systems' biological components, geographic information systems may help operators compensate for some of the feedback (e.g., adaptive management practiced by farmers familiar with locations and species of weed pests within a field) that is often lacking in larger production systems (Ghersa et al., 1994). Such management of temporally and spatially referenced data has also enabled researchers to examine associations of weedy species with various soil and physiographic factors (Andreasen et al., 1991; Dale et al., 1992; Johnson et al., 1999; Dieleman et al., 2000a, 2000b; Burton et al., 2004, 2005). Depending on the strength of a weed species' association with soil or landscape characteristics (edaphic effects) and the spatial stability of the weed population's distribution (i.e., degree of patchiness, population density constancy and persistence at a location) (Gerhards et al., 1997; Johnson et al., 1996; Wiles et al., 1992; Wilson and Brain, 1991), researchers may be able to identify areas in which a species would likely be most harmful to yield. Similarly, it may be possible to identify where the species would be most recalcitrant in the event of invasion or would likely require application of additional or different management tactics (either in type, magnitude or frequency) for acceptable weed control (Burton et al., 2005). In short, to manage weed populations more efficiently, we must have a more complete understanding of the biology of the weeds within the system and how population dynamics vary with respect to site characteristics.
Although considerable effort has been invested in elucidating demographic processes for some weed species (Gonzalez-Andujar and FernandezQuintanilla, 1991; Fernandez-Quintanilla et al., 1987; Lindquist et al., 1995; Naylor, 1972; Sagar and Mortimer, 1976; etc.), few investigations (but see Burton et al., 2004, 2005) have been conducted to test for differences in a species' population dynamics across disparate sub-field environments (e.g., high and low SOC environments) for species known to be associated with particular niche characteristics. Using a multivariate statistical approach, Dieleman et al. (2000b) observed that feral common sunflower (Helianthus annuus L.) presence was positively correlated with SOC. Burton et al. (2004) explored the effect of disparate SOC environments on $H$. annuus emergence and early season seedling survival and suggested that (1) differences in SOC may lead to differential survival among $H$. annuus seedlings receiving a pre-emergence herbicide (PRE) treatment of atrazine and acetochlor [2-chloro- $N$-(ethoxymethyl)- $N$-(2-ethyl6-methylphenyl)acetamide] with $40 \%$ higher seedling survival in high SOC environments, and (2) seedling survival was higher in untreated high SOC furrow microsites in the ridge-tillage system than in untreated low SOC environments.

The ridge-till system is widely employed in Nebraska (USA) and many other states for maize, sorghum and soybean production (Klein et al., 1996). The ridges into which the crop is planted are permanent, with ridge tops being truncated prior to or at the time of planting. Mechanical tactics are employed for weed control in the furrow, followed by a "ridging" operation in which soil from the between row space is moved to the base of the crop row (Wicks and Somerhalder, 1971). Truncation of ridges at planting has been observed to remove 31$37 \%$ of buried weed seeds from the ridges of continuous maize production systems (Forcella and Lindstrom, 1988a; Forcella and Lindstrom, 1988b). Others report potentially higher levels of weed seed removal from the ridge. Assuming that the top $7.6 \mathrm{~cm}$ of soil is moved from the ridges by truncation, the data of Wicks and Somerhalder (1971) indicated that $88 \%$ of seeds occurring in the top $15.2 \mathrm{~cm}$ of ridges (measured before truncation) are removed from the crop row seedbank. Post-planting cultiva- 
tion in the ridge-till system also effectively controls weed seedlings in the furrow (Wicks and Somerhalder, 1971; Wilson, 1993) and resulted in lower average $H$. annuus densities compared to moldboard and disk tillage systems (Wilson, 1993). Cultivation reduced $H$. annuus density by $72 \%$ compared to an unmanaged check plot. However, unacceptably high $H$. annuus seedling densities remained (i.e., 125 plants $10 \mathrm{~m}^{-2}$ ). Cultivation in combination with chemical tactics resulted in much lower $H$. annuus densities (i.e., 2 plants $10 \mathrm{~m}^{-2}$ ).

This paper examines the effects of cultivation, ridging, and SOC environment on juvenile $H$. annuus survival in ridge and furrow microsites and compares $H$. annuus vegetative growth from the time of the ridging operation through maize harvest in high and low SOC environments. Reproductive biomass is also compared across SOC environments as an estimate of fecundity.

\section{Materials and methods}

\subsection{Mechanical tactics}

Survival of $H$. annuus juveniles was observed by direct count before and after tillage was performed (cultivation, which passed within $7-10 \mathrm{~cm}$ of the crop row; and ridging, which moved soil from the furrow to the base of the maize crop) in a continuous maize production field in 1999. The field site was previously described by Burton et al. (2004). Plots consisted of three adjacent subplots, each of which was $1 \mathrm{~m}$ of two neighboring $0.76 \mathrm{~m}$ crop rows and furrows (subplot area $=1.52 \mathrm{~m}^{2}$ ). One subplot was selected at random and assigned an herbicide-treatment. Within each subplot, $60 \mathrm{H}$. annuus seeds were planted at $10 \mathrm{~cm}$ intervals in each of two between row spaces (furrows) and on both sides of each of two crop rows (ridges), such that a total of 20 seeds were planted to furrows and 40 seeds were planted to ridges in each subplot. Seeds were planted in the ridges $4-6 \mathrm{~cm}$ on each side of crop row 1 day after maize planting. Seeds in ridges and furrows were planted to a vertical depth of approximately $4 \mathrm{~cm}$ using a small probe to create a $45^{\circ}$ angle hole. Pre-emergence herbicide was applied 2 days after crop planting to the appropriate subplots in a $0.38 \mathrm{~m}$ band centered on the crop row at one-half the farmer-applied rate of $2.77 \mathrm{~kg}$ ai acetochlor [2-chloro- $N$-(ethoxymethyl)- $N$-(2-ethyl6-methylphenyl)acetamide] and $1.10 \mathrm{~kg}$ ai atrazine per treated ha. A seed pre-treatment of gibberellic acid was used to promote $H$. annuus seed germination and resulted in overall emergence of $68 \%$ in no-herbicide plots (Burton et al., 2004).

Effects of tillage on $H$. annuus survival (recruitment) were determined by comparing pre-cultivation seedling number to the number of juveniles that survived cultivation and ridging treatments across high and low SOC levels and herbicide treated and no-herbicide subplots. Cultivation was performed 30 days after maize planting and ridging was performed 1 week later. The experimental design for mechanical tactics was a split-plot with SOC level as main plot and herbicide treatment as the split-plot. Six high-low SOC plot pairs were distributed across the 64 ha field site (Figure 1). Analysis of variance was performed with the MIXED procedure in $S A S^{\circledR}$ System for Windows Version 8 (SAS Institute, Cary, NC). Rodent herbivory resulted in a total of eight missing plant observations (including all of one subplot), all of which were from low SOC environments. These missing plants were treated as missing observations in statistical analyses.

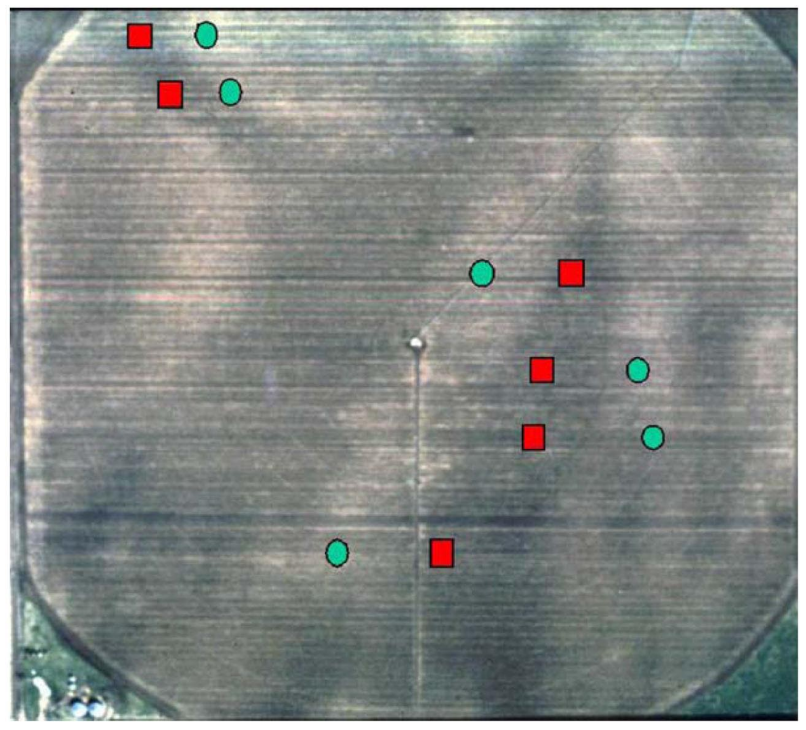

Figure 1. Distribution of plots within 64 ha field located near Shelton, NE. Squares represent high SOC locations and circles represent low SOC locations. Plots within a high-low pair occurred in the same crop rows. 


\subsection{Vegetative growth and reproductive biomass}

Two days after the ridging operation was completed, four surviving juvenile $H$. annuus plants were randomly selected from furrows in each of the two no-herbicide subplots within each of 12 plots. All other $H$. annuus plants within the subplots were removed. Vegetative and reproductive growth characteristics of $H$. annuus were measured in the high and low SOC environments through maize harvest. Canopy height and stem diameter measurements were made on June 23 ( 2 days after ridging), July 9 (maize V10), July 23 (maize anthesis), and September 25 (2 days before maize harvest). Canopy height was measured to the nearest $5 \mathrm{~cm}$ as the highest point of an undisturbed plant. Since many $H$. annuus plants had lodged during the preceding 2 months, stem length was measured on September 25 in addition to canopy height and stem diameter. Stem length was defined as the overall length of the stem regardless of its angle to the ground (i.e., a plant that was upright would have equivalent values for canopy height and stem length). Maize canopy height was measured as described for $H$. annuus until anthesis, when the tassel was included in the height measurement. Stem diameter was measured with a digital caliper to $0.1 \mathrm{~mm}$ at the thickest part of the plant stem. Node number is reported as described by Schneiter and Miller (1981), counting each true leaf of $>4 \mathrm{~cm}$ length or leaf abscission scar.

Each $H$. annuus plant was separated into vegetative (leaves and stems) and reproductive components (flowers and capitula), and dried to constant weight at $70^{\circ} \mathrm{C}$. Flowers were sorted into four classes ( $\leq \mathrm{R} 5, \mathrm{R} 6, \mathrm{R} 7$, and $\geq \mathrm{R} 8$ ) according to phenological development (Schneiter and Miller, 1981). Flowers $\leq \mathrm{R} 5$ were combined because these flowers were considered unlikely to produce seeds of sufficient resources and vigor to survive under normal conditions if the mother plant was killed during maize harvest. Flowers were combined if $\geq R 8$ because flowers of wild $H$. annuus may begin to shatter before floral characteristics (browning of the base of the capitulum) described by Schneiter and Miller (1981) as indicating physiological maturity, R9, were observed.

The experimental design for vegetative and reproductive growth characteristics was equivalent to a randomized complete block with subsampling (higher levels of the original split-plot design were not statistically significant at $a=0.05$ ). Analysis of variance for vegetative and reproductive growth characteristics was also performed using PROC MIXED (Littell et al., 1996). Summary statistics for vegetative growth characteristics and reproductive biomass by plant status were calculated using the UNIVARIATE procedure (SAS, 1999).

\section{Results and discussion}

\subsection{Mechanical weed control}

$H$. annuus survival through mechanical weed control tactics (i.e., cultivation and ridging) did not differ significantly $(P \geq 0.18)$ between SOC environments. However, cultivation resulted in a reduction in the $H$. annuus juvenile population (Figure 2). All plants occurring in the center of the Furrow were killed by cultivation. Within the PRE treated ridge, survival was reduced $(P=0.02)$ from an initial mean of 3.8 plants subplot ${ }^{-1}$ to a mean of 2.5 plants subplot ${ }^{-1}$ (Figure 2). The further reduction of $H$. annuus to a mean of 1.7 plants subplot ${ }^{-1}$ by ridging was not statistically different from the seedling abundance observed after cultivation $(P=0.13)$. As a consequence of these two operations, the abundance of recruited plants (i.e., the number that

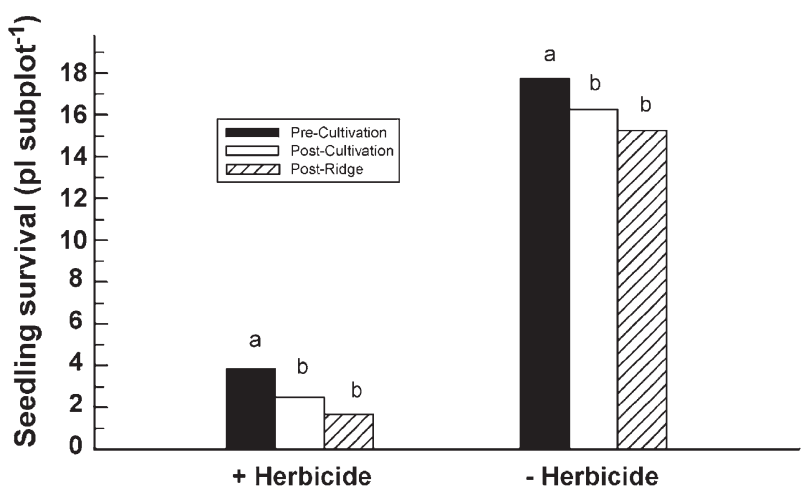

Figure 2. Effect of mechanical tactics on $H$. annuus survival in the ridge microsites in herbicide treated and control subplots. Within a treatment, tactics that are annotated by the same letter are not significantly different at $a=0.05$. All seedlings in the furrow microsite were killed by cultivation. 
survived all mechanical tactics) was different from the abundance of seedlings (pre-cultivation) that survived the PRE treatment $(P<0.001)$. Control (no herbicide) subplots were similar in terms of the significance of pairwise comparisons of initial seedling abundance (pre-cultivation) and observed abundance following cultivation or ridging (Figure 2). The total actual reduction in juvenile abundance due to mechanical tactics in control subplots (2.6 plants subplot $^{-1}$ ) was somewhat greater than was observed in herbicide treated subplots (2.1 plants subplot ${ }^{-1}$ ), but the proportional reduction in observed plant density was smaller (15\% versus $55 \%$, respectively). Survival in the control subplots prior to cultivation, after cultivation and after ridging was 17.8, 16.2, and 15.2 plants subplot ${ }^{-1}$, respectively.

Although no differences in weed management outcomes were observed as a consequence of SOC environment in this year, the interaction of soil characteristics and landscape position to produce wet conditions at the time of cultivation can affect weed management outcomes. Areas with wetter soil are sometimes avoided (i.e., left uncultivated) or might result in soil clumps after cultivation that allow re-rooting of weeds that would have been killed under normal (i.e., drier) conditions.

\subsection{Vegetative growth}

Unless otherwise noted, all $H$. annuus growth comparisons were made between subplots not treated with herbicide. Nearly all plants were erect at the 23 July sampling date (maize anthesis) and mean $H$. annuus canopy height $(\sim 220 \mathrm{~cm})$ was less than the $\sim 250 \mathrm{~cm}$ mean canopy height of maize (Table 2). Despite $>100 \mathrm{~cm}$ increase in mean stem length (Table 2) over the mean canopy height at the previous observation date, $H$. annuus mean canopy height did not demonstrate a net increase in canopy height by maize harvest due to bending and lodging of $H$. annuus stems. That is to say, had $H$. annuus plants not lodged or bent, they would have been on average $70 \mathrm{~cm}$ taller than the maize crop.

$H$. annuus canopy height, stem length, stem diameter, and node number were not affected by SOC environment (Table 2). This is in part due to the large range of values observed within each SOC environment for each characteristic (Table 1). Vegetative biomass at harvest also did not differ $(P=0.40)$ between SOC environments, with means of 459 and $409 \mathrm{~g}$, respectively. Mean growth characteristic values for high SOC were often, even if only slightly, greater than were observed in low SOC environments. While small differences in growth characteristics can lead to differences in population dynamic outcomes, these differences are small compared to those observed for seedling survival in high and low SOC environments in related experiments (Burton et al., 2004).

In discussing plant vegetative growth, Harper (1977, p. 777) asserts that while there is an advantage conferred to a plant when it intercepts more light than its competitors (and shades its competitors), there is "no intrinsic advantage to the individual from being high (there are some real disadvantages in the amount of non-reproductive tissue to be supported), only an advantage from being higher than neighbors. It is being higher, not just

Table 1. Vegetative growth characteristics of feral H. annuus at maize harvest (September 25, 1999) when grown in habitats that differed in soil organic carbon (SOC) level

\begin{tabular}{lllccc}
\hline SOC level & Vegetative growth characteristic & $N^{\mathrm{a}}$ & LS mean & Std error & Range \\
\hline High & Canopy height $(\mathrm{cm})$ & $46^{\mathrm{b}}$ & 222 & 15 & $60-370$ \\
& Stem length $(\mathrm{cm})$ & 46 & 340 & 6 & $240-405$ \\
& Stem diameter $(\mathrm{mm})$ & 46 & 33.2 & 1.3 & $16.6-45.8$ \\
\multirow{4}{*}{ Low } & & & & 16 & $10-395$ \\
& Canopy height & 37 & 192 & 7 & $270-410$ \\
& Stem length & 37 & 328 & 1.4 & $16.5-46.7$ \\
\hline
\end{tabular}

Standard error is standard error of the least squares treatment mean.

a $N$, number of observations in the estimate; LS mean, least-squares mean; Std error, standard error of the treatment mean.

$\mathrm{b}$ Two of the original 48 plants in the high SOC environments died during the experiment. Although only three plants died in the low SOC environments during the experiment, eight seedlings were eliminated by rodent activity. 
Table 2. Average canopy height, stem length, stem diameter and node number of feral $H$. annuus growing near maize crop rows in areas of high $(\mathrm{H})$ and low $(\mathrm{L})$ soil organic carbon

\begin{tabular}{|c|c|c|c|c|c|c|c|c|}
\hline \multirow[t]{2}{*}{ Sampling date } & \multicolumn{2}{|c|}{ Canopy height $(\mathrm{cm})$} & \multicolumn{2}{|c|}{ Stem length $(\mathrm{cm})$} & \multicolumn{2}{|c|}{ Stem diameter (mm) } & \multicolumn{2}{|c|}{ Node number } \\
\hline & $\mathrm{H}$ & $\overline{\mathrm{L}}$ & $\mathrm{H}$ & $\overline{\mathrm{L}}$ & $\mathrm{H}$ & $\overline{\mathrm{L}}$ & $\mathrm{H}$ & $\mathrm{L}$ \\
\hline June 23 (post-ridging) & $63.9(4.0)$ & $62.0(4.1)$ & - & - & $12.7(0.8)$ & $11.9(0.9)$ & $12.6(0.6)$ & $11.5(0.6)$ \\
\hline July 9 (maize V10) & $128.6(6.3)$ & $129.4(7.2)$ & - & - & $21.2(1.2)$ & $20.2(1.4)$ & $22.5(0.8)$ & $22.0(0.9)$ \\
\hline July 23 (maize anthesis) & $217.2(7.1)$ & $218.3(7.4)$ & - & - & $24.9(0.8)$ & $24.0(0.9)$ & $30.3(1.0)$ & $29.1(1.1)$ \\
\hline September 25 (maize harvest) & $222.2(14.7)$ & $191.7(15.8)$ & $340.2(5.9)$ & $328.1(6.6)$ & $33.2(1.3)$ & $31.6(1.3)$ & - & - \\
\hline
\end{tabular}

Standard error of the mean is given in parentheses.

high, that pays." Resources invested in producing and supporting vertical growth are resources not used in reproductive growth. Our data indicate that there may be other negative repercussions. In $\mathrm{Ne}-$ braska maize fields, $H$. annuus can grow to overtop the crop by continuing vertical vegetative growth after maize has tasseled. The competitive advantage of a longer period of vegetative growth may, however, leave $H$. annuus at risk of bending, lodging, or stem breakage due to wind exposure and weight-especially as stem stress increases due to increasing reproductive biomass above the shelter of an already tall crop canopy. Plants whose stems cannot support the combined stresses of wind and weight were often partially supported by crop plants, but may fall between rows or crop plants. These plants are shaded by the crop and may suffer broken stems that allow insect infestation (M. Burton, pers. observation). Lodged plants suffered reduced fitness as measured by reproductive biomass (Table 3). In the present experiment, plants that lodged to the ground (i.e., branches and stems were in contact with the soil) usually died and were beginning to decay at harvest. Although rodent activity resulted in eight fewer available seedlings in the low SOC environments at the outset of this experiment, a similar number of plants died in each SOC environment between juvenile and reproductive stages of growth (two and three plants died in high and low SOC environments, respectively).

\subsection{Reproductive biomass}

Survival of $H$. annuus decreased significantly $(P<0.01)$ during the period between July 23 and maize harvest. All juvenile seedlings that were selected after mechanical weed control tactics were still living on July 23 . By September 25 , some plants had died, suffered broken stems, or were lodged within the maize canopy. From July 23 to September 25, average plant density declined from 3.82 to 3.39 plants per subplot. Plants that produced little reproductive biomass (i.e., $<5 \mathrm{~g}$ dryweight) by maize harvest were considered to have failed to produce viable seeds.

Mean total reproductive biomass (floral dryweight from all reproductive stages) was not different between SOC locations $(P=0.49)$. Mean total reproductive biomass for high and low SOC location was 150 and $134 \mathrm{~g}$, respectively. Since $H$. annuus plants may be killed by maize harvesting equipment, total reproductive biomass may overestimate fecundity. Although $H$. annuus disk flowers develop and are fertilized progressively from

Table 3. Average reproductive biomass of feral $H$. annuus by plant status and reproductive biomass phenological categories at crop harvest

\begin{tabular}{llrrrr}
\hline Status $^{\mathrm{a}}$ & $\begin{array}{l}\text { Reproductive } \\
\text { category }\end{array}$ & $N^{\mathrm{b}}$ & Mean & \multicolumn{1}{c}{$\begin{array}{c}\text { Std } \\
\text { error }\end{array}$} & Range \\
\hline UPRIGHT & Total & 37 & 187.6 & 16.9 & $41.5-465.1$ \\
& $\geq \mathrm{R7}$ & 37 & 81.4 & 11.1 & $0-270.3$ \\
BENT & Total & 38 & 166.8 & 16.4 & $2.8-359.5$ \\
& $\geq \mathrm{R7}$ & 38 & 65.2 & 10.5 & $0-269.5$ \\
LODGED & Total & 18 & 70.7 & 17.4 & $0.7-218.1$ \\
& $\geq \mathrm{R7}$ & 18 & 27.7 & 9.0 & $0-120.2$ \\
DEAD & Total & 8 & 1.0 & 1.0 & $0-8.2$ \\
& $\geq \mathrm{R7}$ & 8 & 0.6 & 0.6 & $0-4.5$ \\
\hline
\end{tabular}

Data pooled from all subplots (including four subplots from a related experiment). Plant status was determined as the proportion of canopy height to stem length.

a UPRIGHT, proportional height $\geq 0.70 ;$ BENT, $\geq 0.50$; LODGED, <0.50; dead plants were categorized as dead regardless of proportional height observed at harvest.

${ }^{\mathrm{b}} N$, number of observations in the estimate; Std error, standard error of the mean. 
the disk perimeter to the center, seeds at the perimeter of R6 flowers were poorly filled and, although fertilized, were considered unlikely to be capable of producing a viable seedling under normal circumstances. Consequently, we tested for an effect of SOC on combined reproductive biomass from the R7 and later phenologies. Again, no effect of SOC was observed $(P=0.59)$ between high and low SOC locations with means of 62 and $55 \mathrm{~g}$, respectively.

\section{Conclusions}

While $H$. annuus density decreased as a result of mechanical cultivation, the actual magnitude of the decrease was small when juvenile plants were growing near the crop row. Similarly, only small decreases in $H$. annuus plant density were observed during the course of the crop season. The range of total reproductive biomass for untreated $H$. annuus (0-465 g) was similar to that of 23 herbicide treated plants that were allowed to grow in neighboring subplots $(0-409 \mathrm{~g})$. Although floral development lagged behind that of the untreated plants (R7-R9 mean of herbicide treated plants was $39 \mathrm{~g}$ compared with $61 \mathrm{~g}$ for untreated plants), herbicide treated escapes observed elsewhere in the field demonstrated considerable reproductive capacity. Late season (after maize anthesis) lodging of $H$. annuus resulted in decreased reproductive biomass production. Unlike early season survival (Burton et al., 2004), SOC did not affect survival, growth, or reproductive capacity of $H$. annuus. The lack of differences here suggests that SOC's primary role in regulation of $H$. annuus populations in well-fertilized, irrigated maize occurs prior to mechanical cultivation. However, additional multi-year studies should be conducted to confirm this result across a similar or broader range of soil environments and locations.

\section{Acknowledgments}

This research was partially supported by the USDA National Research Initiative. The authors gratefully acknowledge the assistance of Mr. Paul Gangwish of P.G. Farms, Inc.

\section{References}

Andreasen et al., 1991 C. Andreasen, J. C. Streibig, and $\mathrm{H}$. Haas, Soil properties affecting the distribution of 37 weed species in Danish fields, Weed Res. 31 (1991), pp. 181-187.

Burton et al., $2004<$ M. G. Burton, D. A. Mortensen, D. B. Marx, and J. L. Lindquist, Factors affecting the realized niche of common sunflower (Helianthus annuus) in ridge-tillage corn: seed germination, emergence, and survival, Weed Sci. 52 (2004), pp. 779-787.

Burton et al., $20054 \mathrm{M}$. G. Burton, D. A. Mortensen, and J. L. Lindquist, Environmental characteristics affecting Helianthus annuus distribution in a maize production system, Agric. Ecosyst. Environ. (2005) (in press).

Dale et al., 19924 M. R. T. Dale, A. G. Thomas, and E. A. John, Environmental factors including management practices as correlates of weed community composition in spring seeded crops, Can. J. Bot. 70 (1992), pp. 1931-1939.

Dieleman et al., 2000a 4 J. A. Dieleman, D. A. Mortensen, D. D. Buhler, C. A. Cambardella, and T. B. Moorman, Identifying associations among site properties and weed species abundance. I. Multivariate analysis, Weed Sci. 48 (2000) (5), pp. 567-575.

Dieleman et al., 2000b J. A. Dieleman, D. A. Mortensen, D. D. Buhler, and R. B. Ferguson, Identifying associations among site properties and weed species abundance II. Hypothesis generation, Weed Sci. 48 (2000) (5), pp. 576-587.

Fernandez-Quintanilla et al., 1987 ४ C. FernandezQuintanilla, L. Navarrette, C. Torner, and J. L. Andujar, Influence of herbicide treatments on the population dynamics of Avena sterilis ssp. ludoviciana (Durieu) Nyman in winter wheat crops, Weed Res. 27 (1987), pp. 375-383.

Forcella and Lindstrom, 1988a 4 F. Forcella and M. J. Lindstrom, Movement and germination of weed seeds in ridge-till crop production systems, Weed Sci. 36 (1988), pp. 56-59.

Forcella and Lindstrom, 1988b 4 F. Forcella and M. J. Lindstrom, Weed seed populations in ridge and conventional tillage, Weed Sci. 36 (1988), pp. 500-503.

Gerhards et al., 1997 R. Gerhards, D. Y. Wyse-Pester, D. Mortensen, and G. A. Johnson, Characterizing spatial stability of weed populations using interpolated maps, Weed Sci. 45 (1997), pp. 108-119.

Ghersa et al., $1994<$ C. M. Ghersa, M. L. Roush, S. R. Radosevich, and S. M. Cordray, Coevolution of agroecosystems and weed management, BioScience 44 (1994), pp. 85-94. 
Gonzalez-Andujar and Fernandez-Quintanilla, $1991 \mathrm{~J}$. L. Gonzalez-Andujar and C. Fernandez-Quintanilla, Modelling the population dynamics of Avena sterilis under dry-land cereal cropping systems, J. Appl. Ecol. 28 (1991), pp. 16-27.

Harper, 1977 J. L. Harper, Population Biology of Plants, Academic Press, New York, NY (1977) 892 pp.

Johnson et al., $1999<$ G. A. Johnson, M. G. Krusemark, and J. Bell, Using a GIS to study the interaction of terrain attributes and weed occurrence. Annual Meeting of the Weed Science Society of America, San Diego, 39:333 (1999). WSSA Abstracts, Champaign, IL, USA.

Johnson et al., 19954 G. A. Johnson, D. A. Mortensen, and A. R. Martin, A simulation of herbicide use based on weed spatial distribution, Weed Res. 35 (1995), pp. 197-205.

Johnson et al., $1996<$ G. A. Johnson, D. A. Mortensen, and C. A. Gotway, Spatial and temporal analysis of weed seedling populations using geostatistics, Weed Sci. 44 (1996), pp. 704-710.

Klein et al., $1996<$ R. N. Klein, G. A. Wicks, and R. G. Wilson, Ridge-till, an integrated weed management system, Weed Sci. 44 (1996), pp. 417-422.

Lindquist et al., $1995<\mathrm{J}$. L. Lindquist, B. D. Maxwell, D. D. Buhler, and J. L. Gunsolus, Velvetleaf (Abutilon theophrasti) recruitment, survival, seed production, and interference in soybean (Glycine max), Weed Sci. 43 (1995), pp. 226-232.

Lindquist et al., $1998<$ J. L. Lindquist, J. A. Dieleman, D. A. Mortensen, G. A. Johnson, and D. Y. Wyse-Pester, Economic importance of managing spatially heterogeneous weed populations, Weed Tech. 12 (1998) (1), pp. 7-13.

Littell et al., $1996 \varangle$ R. C. Littell, G. A. Milliken, W. W. Stroup, and R. D. Wolfinger, SAS System for Mixed Models, Statistical Analysis Systems Institute, Cary, NC (1996).

Mitchell et al., $1996<$ K. M. Mitchell, D. R. Pike, and $\mathrm{H}$. Mitasova, Using a geographic information system (GIS) for herbicide management, Weed Tech. 10 (1996), pp. 856-864.

Naylor, $1972<$ R. E. L. Naylor, Aspects of the population dynamics of the weed Alopecurus myosuroides Huds. in winter cereal crops, J. Appl. Ecol. 9 (1972), pp. 127-139.
Novak et al., 1997 J. M. Novak, T. B. Moorman, and C. A. Cambardella, Atrazine sorption at the field scale in relation to soils and landscape position, J. Environ. Qual. 26 (1997), pp. 1271-1277.

Prather and Callihan, $1993<$ T. S. Prather and R. H. Callihan, Weed eradication using geographic information systems, Weed Tech. 7 (1993), pp. 265-269.

Sagar and Mortimer, $1976 \varangle$ G. R. Sagar and A. M. Mortimer, An approach to the study of the population dynamics of plants with special reference to weeds, Appl. Biol. 1 (1976), pp. 1-47.

SAS Institute Inc, 1999 \&AS Institute Inc., 1999. SAS ${ }^{\circledR}$ Procedures Guide, Version 8. SAS Institute Inc., Cary, NC, 1643 pp.

Schneiter and Miller, $1981<$ A. A. Schneiter and J. F. Miller, Description of sunflower growth stages, Crop Sci. 21 (1981), pp. 901-903.

Wicks and Somerhalder, $1971 \triangleleft$ G. A. Wicks and B. R. Somerhalder, Effect of seedbed preparation for corn on distribution of weed seed, Weed Sci. 19 (1971) (6), pp. 666-669.

Wiles et al., $1992<$ L. J. Wiles, G. W. Oliver, A. C. York, H. J. Gold, and G. O. Wilkerson, Spatial distribution of broadleaf weeds in North Carolina soybean (Glycine max) fields, Weed Sci. 40 (1992), pp. 554-557.

Wilson, $1993 \varangle$ R. G. Wilson, Effect of preplant tillage, post-plant cultivation, and herbicides on weed density in corn (Zea mays), Weed Tech. 7 (1993), pp. 728-734.

Wilson and Brain, $1991<$ B. J. Wilson and P. Brain, Long-term stability of distribution of Alopecurus myosuroides Huds. within cereal fields, Weed Res. 31 (1991), pp. 367-373.

Wilson et al., $1993<\mathrm{J}$. P. Wilson, W. P. Inskeep, P. R. Rubright, D. Cooksey, J. S. Jacobsen, and R. D. Snyder, Coupling geographic information systems and models for weed control and groundwater protection, Weed Tech. 7 (1993), pp. 255-264. 